\title{
Design of Bentor Steering System Using Tie-Rod
}

\author{
Zulhaji ${ }^{\#}$, Muhammad Yahya ${ }^{\#}$ \\ ${ }^{\#}$ Education Automotive Engineering, Makassar State University, Pettarani Street, Makassar, 90224, Indonesia \\ E-mail: zulhaji.otomotif@unm.ac.id,m.yahya@unm.ac.id
}

\begin{abstract}
The mobility of the people in the suburbs is very high, especially the Angkot (Pete-pete) only reaches the main road so that to take the remote lane is now used Bentor transportation that can take remote lanes and housing. The issue of eradicating ridges has been developing in the cemetery because Bentor transport vehicles are not roadworthy because to turn them must move like a place where passengers interfere with passenger safety. This, of course, will reduce employment and increase unemployment, so the policy recommendations for benthic operations are very open, especially in areas not covered by public transportation. These recommendations include changing the steering system so that only the front wheel moves when turning. The results of the design and research of the Bentor steering system using a tie-rod make it easier for the driver to turn and provide a sense of security and comfort to the passengers because they are no longer driven when turning, the driver does not bend his body, this indicates that the steering system can function properly. The results of the Bentor steering measurements using a tie rod are obtained as appropriate camber, caster and toe angles and have a turning angle of $40^{\circ}$, so that they can turn better than ordinary Bentor.
\end{abstract}

Keywords — bentor; steering system; tie-rod; security; comfort.

\section{INTRODUCTION}

Mobility of people domiciled in the city and on the outskirts of the city is currently high to fulfill their needs. Community mobility centers are in markets that provide the needs of the local community, to travel from home to market, public or city transportation (Pete-pete) is needed. One alternative transportation facility that is currently popular among the public as a means of transportation is a motorized rickshaw with the term "Bentor." The community favors this Bentor because it is easy to find, agile and fast in the sense that anytime passengers will depart Bentor is always ready and does not need to wait for other passengers, because the carrying capacity is a maximum of 2 people.

The presence of clashes in Sungguminasa makes pedicab drivers unable to do much, so many pedicab drivers turn to become Bentor drivers [1]. According to the author's interview with several carpenters in the Sungguminasa area, construction workers in this area are Pedicab drivers and motorcycle taxi drivers who make their fortunes with economic improvements. Low economic people prefer to switch to Bentor drivers because they have relatively better. The poverty rate in Indonesia has increased; in 2012 the poverty rate was 8.4 percent of Indonesia's total population. In 2013 , this value rose to 8.5 percent and rose to 8.2 percent in 2014 . The number of people living below the poverty line in 2016 reached 66,780 people or 4.56 percent of the total population in Makassar City [2]. With the existence of
Bentor, the economy of the community can increase as promised work.

Bentor is very popular with the community because of the speed and density of service time provided by the driver. In contrast to Pete-pete who always stops to transport passengers on the streets. Increased activity of the community movement is faced with the problem of imbalance between the provision of infrastructure and means of transportation, giving rise to various traffic problems that have an impact on public losses (cost and time), and are not easy to overcome by the Government.

\section{A. Bentor Legality}

Fast growing, the level of development of the community's socio-economic activities is quite high, so it is very dependent on various modes of transportation (private vehicles and public passenger vehicles), which are used by the community in carrying out daily activities. Bentor is a motorcycle that has a two-wheeled passenger front (similar to a Pedicab or three wheels) that can accommodate a maximum of 2 people sitting side by side, like a Pedicab with a motorbike engine. Uniquely, this bent can also carry passengers in the back, different from Pedicabs.

According to Yamin Jinca, the presence of benthic raises a public reaction that demands the existence of operational legality, in the form of Bentor mode status in the form of a decree or set of transportation policies issued by the Regional Government. Bentor has grown and developed quite rapidly since 2003 and has become one of the 
primadonnas of alternative transportation. Bentor has the ability to reach all cities / rural areas, travel time and operations, as well as affordable costs for the community and door to door service or ready to pick up and wait, making its competitiveness quite high, to compete with Angkot, Oplet/Pete-pete, traditional rickshaws and motorcycle taxis in transportation services to the community.

However, the Bentor character is not enough to guarantee the recognition/sustainability as formal transportation, if it is not supported by a vehicle movement system that is roadworthy with a high level of safety, planned traffic engineering, and supported by formal rules/regulations and management of transportation business professional. Another impact is the increasing resistance of traffic movements due to the development of the Bentor population. Today's estimates have reached tens of thousands of motorized vehicles that will replace the functions of traditional rickshaws.

According to article 2 of PP No. 41 of 1993 concerning Road Transportation, it is stated that the transportation of people by motorized vehicles is carried out using motorbikes, passenger cars, bus cars, and special vehicles. However, in Article 4 of the same regulations, transportation of people by public vehicles is carried out by using a bus or passenger car, so legality is only given to bus cars or passenger cars.

Bentor existence has become a polemic of pros and cons in the community, especially for regional legislators, as channeling the aspirations of the people to fight for Bentor's engineering results from the public and executives on the underlying policies/regulations. From the physical aspect, Bentor does not have standardized forms as stipulated in the legislation, so that the level of security and comfort of the use of these vehicles cannot be accounted for. The Directorate General of Land Transportation once gave an example of clashing with the driver in front according to the Decree of the Director General of Land Transportation 1109 / AJ.402 / DRJD / 2008, concerning ratification of design and engineering of houses (carrosserie) based on the Kanzen type KR 125 motorized vehicle as a vehicle motorized tricycle for passenger transportation. Further provisions have not yet been issued.

Based on Law No. 22 of 2009, the existence of benthic does not have a strong legal basis as a means of public transportation, and this will undoubtedly affect the quality and operational sustainability of the Bentor transportation service itself [3]. On the other hand, the presence of benthic is very much needed by low-income people and those in rural areas of the big cities. The existence of Bentor transport is one of them is reducing the problem of unemployment both in urban and rural areas because many unemployed people use these facilities as an alternative to finding work. The economic turnaround of the Bentor community is quite potential as a driver of people's economy, another solution is that several cities have issued a Decree on Bentor Arrangement as an operational reference, among others, Mayor of Banda Aceh Decree No.551.21 / 02/2005 concerning Public Transport Business Licenses, Decree of Gorontalo Mayor No. 1 of 2007 concerning Operation Arrangements for Bentor vehicles [4].

\section{B. Accidents Bentor}

Bentor construction is the adoption of a Pedicab, by removing the steering wheel construction of a motorcycle and front brake and then replacing it with a two-wheeled tub that can accommodate Pedicab-like passengers. Ironically, the steering wheel is not separated from the occupant, so when you turn it must move like a passenger in front of the driver. What's more, if it turns on damaged road conditions, the driver must use assistance with a push of the foot on the passenger, this will also affect the driver which can cause stiffness in the legs. Bentor drivers usually rarely wear standard helmets.

The steering system of Bentor is a component or construction that is very urgent because to control the Bentor to run properly using the steering wheel both on the straight road and when turning. Furthermore, the Bentor position when turning is moving like a passenger in front of the driver, so the driver must move the entire body and passengers to deflect Bentor. This, of course, will require a few driver power.

According to Putra [5], in general, the performance of vehicles can be divided into three types, (1) the ability of vehicles to drive and carry a load, this capability is called vehicle traction performance; (2) the ability of the vehicle to turn to maintain the stability of its direction, and to be easily controlled so as to avoid accidents, this capability is called the vehicle's direction stability performance; (3) the ability of vehicles to make passengers comfortable and to secure riders and passengers from collisions due to accidents so that drivers or passengers can avoid injury, this ability is called the performance of vehicle safety. The design of the steering system on the Bentor using a tie-rod can add good Bentor performance.

According to Haris, "the Bentor is very prone to causing accidents on the road because the large model takes too much space. Therefore, the traffic police must be proactive in controlling", so that it is not feasible to operate on the main road that is crowded with vehicles. Bentor just like operating in an environmental road. Not a protocol. However, the reality now is that there are quite a lot of trees operating on the main roads.

Bent accidents are generally caused by heavy steering construction to be controlled, besides that there are human error factors namely reckless drivers in the streets. Based on 2013 traffic police statistics, there are currently 1,400 accidents caused by benthic. This accident is caused by an average steering system that is difficult to control and braking, so an accident is unavoidable.

\section{Design Goals}

Safety and comfort in driving is a necessity that is acceptable to passengers and drivers, including alternative transportation. Passenger safety must be supported by vehicle safety systems including good steering and braking systems. Passenger comfort must be supported by a suspension system that is on the Bentor, and the comfort of passengers and drivers must be supported by ergonomics in driving both on a straight road and when turning. Like the fact that there are Bentor operating in the South Sulawesi region, especially in Somba Opu, when turning, Bentor must be moved in front of the passenger. 
This can cause discomfort and feel insecure to passengers who are in front, besides that in terms of ergonomics. The driver must tilt the body off to the left or right to deflect the bend so that the position of the driver's spine follows the sloping body. Based on the description that has been stated, the purpose of this design is to design a Bentor steering system with a direct steering system using a tie-rod so that when turning only the wheels are moving, and the driver's position is not tilted to turn the front body.

\section{MATERIALS AND METHOD}

\section{A. Material}

1) Bentor: Bentor is a motorcycle that has a twowheeled passenger front (similar to a Pedicab or three wheels) that can accommodate a maximum of 2 people sitting side by side, like a Pedicab with a motorbike engine. Uniquely, this bent can also carry passengers in the back, different from Pedicabs. Bentor construction is the adoption of a Pedicab, by removing the steering wheel construction of a motorcycle and front brake and then replacing it with a two-wheeled tub that can accommodate Pedicab-like passengers. Ironically, the steering wheel is not separated from the occupant, so when you turn it must move like a passenger in front of the driver. What's more, if it turns on damaged road conditions, the driver must use assistance with a push of the foot on the passenger, this will also affect the driver which can cause stiffness in the legs.

2) Steering System: The steering system is one of the systems contained in the vehicle chassis, the steering system (steering system) is the name for all components that carry movement from the wheel/steering handlebars to the wheels above the road surface [6]. The steering function is to bend the wheel or direct the course of a motorcycle [7], namely by changing the direction of the vehicle and the speed of the vehicle. This change of direction is done by moving or deflecting the front wheels of the vehicle and keeping the position stable. The way it works is when the steering wheel (steering wheel) is moved or rotated, the steering column (steering column) then continues the round to the steering gear rotation (steering gear). This steering gear functions to enlarge the swivel moment to produce more power to move the front wheel through steering links (steering linkage).

How the Steering System works: When the driver turns the steering wheel, the main shaft connected to the steering wheel rotates. At the end of the shaft there are worm gears and nuts on the gearbox, to increase power and change the rotary motion of the steering wheel to the back and forth of the pitmen arm. The arm commitment continues the movement through the drag link to the steering corner lever and is divided into the two front wheels. Recirculating Ball Type. How it works: When the driver turns the steering wheel, the main shaft that is connected to the steering wheel turns. At the end of the main working shaft of the worm gear and nut on the steering wheel, the wheel adds power and moves the rotary motion from the steering wheel to the forward-backward movement of the pitmen arm.

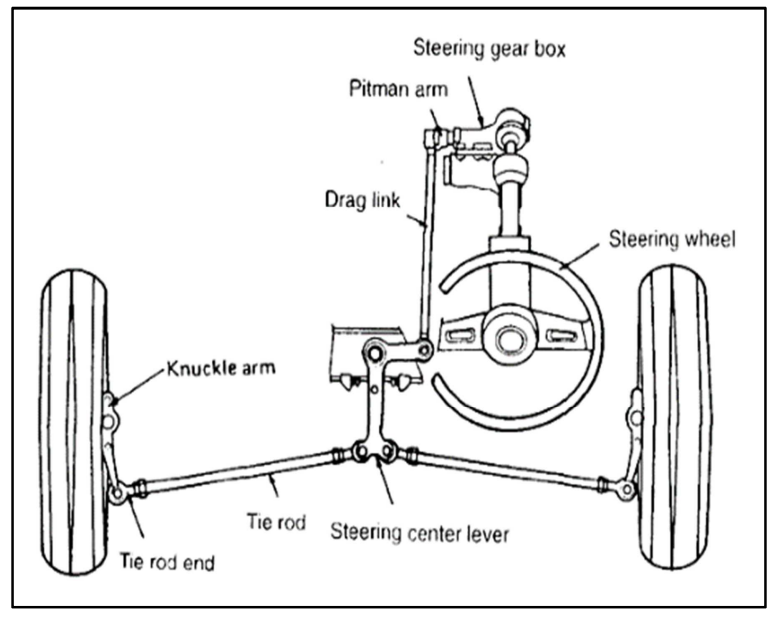

Fig. 1. Steering System

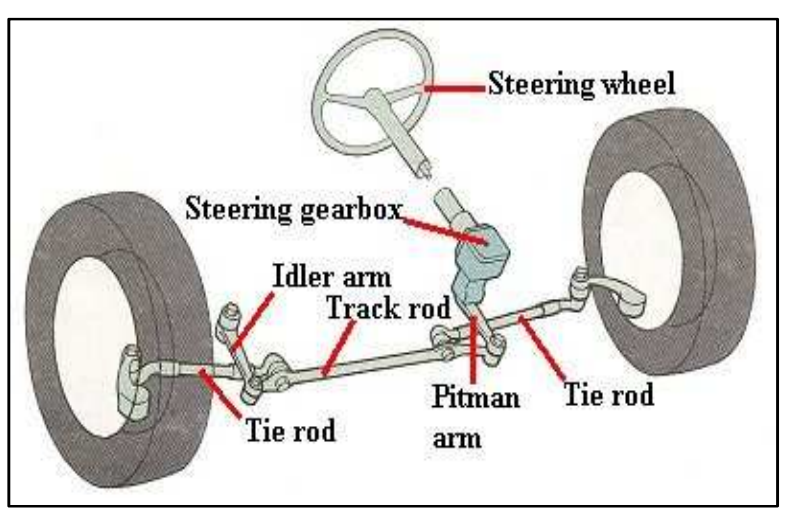

Fig. 2. Construction of a Recirculating Ball Type Steering System

Connecting arms (linkage), connecting rod (relay rod), tie rod, idle arm and knuckle arm connected to the tip of the pitmen arm. All of these components work to move the swivel force from the steering wheel to the front wheels by rotating the ball joint on the lower arm (lower arm) and the upper bearing which is connected with shock absorbers to prevent jerking.

Rack and Pinion Type. How it works: When the steering wheel is rotated, the steering shaft and pinion rotate and move the rack so that the rack changes the rotary motion to a horizontal motion moving to the left or right side, this movement pushes and pulls the wheel through the tie rod and knack arm. this causes the wheels to rotate in the same direction.

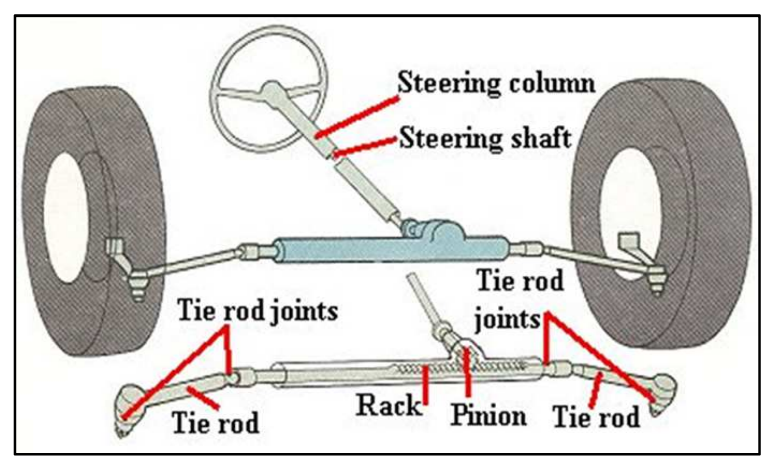

Fig. 3. Construction of Rack and Pinion type Steering systems. 
Rack and pinion type steering is much more efficient for the driver to control the front wheels. The pinion connected to the main shaft of the steering through the intermediate shaft is related to rack.

3) Front Wheel Alignment: For the suspension system and steering to be used properly, it is necessary to adjust the front wheels. Front wheel alignment is very much needed to make it easier to adjust the steering handlebars or drive, as well as vehicle and passenger safety that can be guaranteed [8]. In the steering system of the car, there are several front wheels as a steering wheel for the vehicle namely camber, caster, toe angle.

Camber is the slope of the front wheel against the vertical line of the wheel seen from the front of the vehicle. If the outward slant is called positive camber, and if it is tilted inward it is called negative camber. Positive camber serves to allow the formation of zero camber when the vehicle is given a load, and reduce the burden on the steering. Negative camber serves to prioritize the vehicle can be straight and stable. Negative camber reduces ground camber (tilt of the vehicle when turning) and perfects turning capability. Zero camber causes driver stability to decrease [9].

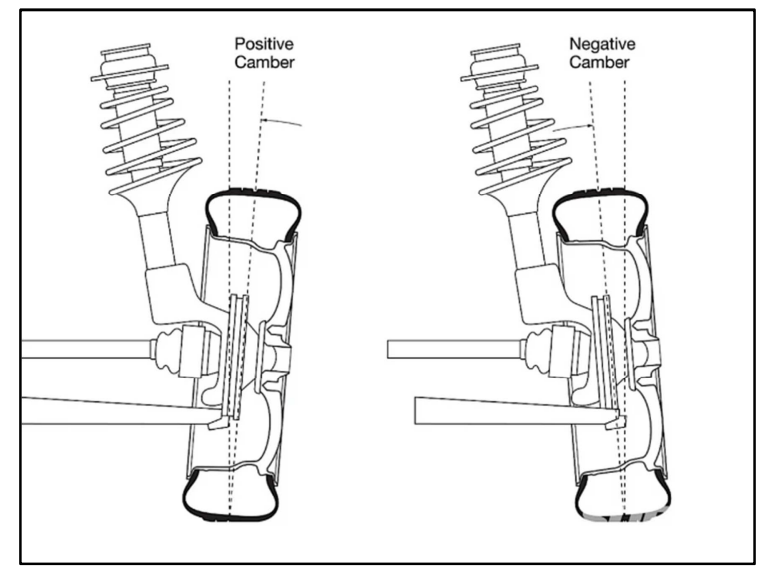

Fig. 4. Camber.

Caster is the slope of the front wheel axis towards the vertical line of the wheel seen from the side of the vehicle if the slope of the steering axis toward the back is called a positive caster. Whereas if the slope of the steering axis towards the front is called a negative caster. Positive caster works for steering stability and steering power after turning. Negative caster makes steering light, but the stability of the vehicle when walking straight is reduced [10].

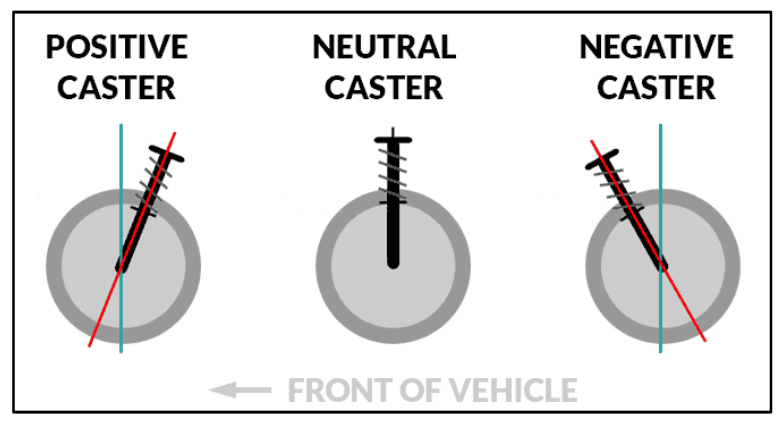

Fig. 5. Caster
Toe Angel consists of the arrangement of toe in and toes out. Vehicles can be called having toe-in if the distance of the front wheel (A) is smaller than the back of the front wheel (B) (seen from above). Instead, the opposite arrangement is called toe out and is expressed in units of millimeters (B - A) [10].

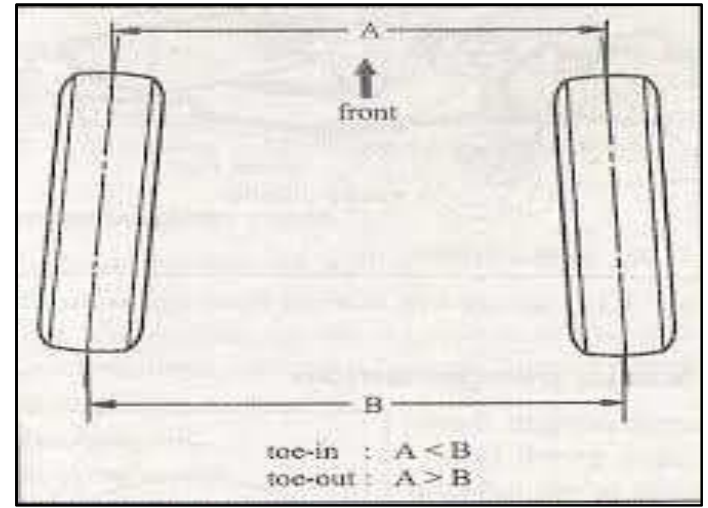

Fig. 6. Toe Angel

4) Safety Bentor: Because the Bentor construction is adopted from a pedicab, which means that the steering wheel is the entire front of the Bentor, including the body of the passenger. Seeing this construction, passenger safety is very prone to accidents, because it is difficult to control the direction of the vehicle with heavy steering to be driven, namely by moving the body and passengers in front. Moreover, when turning is needed the power to move the front of the passenger seat, this will undoubtedly reduce the comfort of passengers who are in front, so that construction like this should not occur and must do modifications. Also, the driver's body position will be either left or right, causing the spine to tilt to follow the body position.

5) Comfort Bentor: Suspension is a system on vehicles that can reduce vibrations caused by uneven road surfaces. The suspension connects the vehicle frame with the wheels and functions as follows:

- During walking, the vehicle together with the wheels absorbs vibration, oscillation, and shock from the road surface, this is to protect the rider and increase comfort and stability.

- Move the braking force and force to the body through friction between the road and the wheels.

- Reduces spring swing.

Leaf springs are used for vehicles with heavy loads. Leaf springs usually consist of several spring leaves tied with a flashlight pin and closed with a bracket. Vehicle springs, especially those that use hard springs that can support a heavy vehicle load, do not have soft motion, while a soft spring with Shock Absorber cannot support heavy loads but can work gently, so combining the two this type of spring is highly recommended for better vehicle comfort [11].

6) Ergonomics: Ergonomics is one part of occupational health, which focuses on adjusting work to the condition of the human body to create comfortable conditions. Ergonomics if applied appropriately will produce several benefits including improving work, such as increasing work 
speed, accuracy, work safety, reducing energy and excessive fatigue.

Comfort is an element of human feeling that arises as a result of minimal or no interference with bodily sensations [12]. Some people claim that comfort is everything appropriate and in harmony with the use of space, both with space itself and with various shapes, textures, colors, symbols, sounds or whatever. Or in other words that comfort is largely determined by the balance between factors in humans with external environmental factors that influence it. With comfortable environmental conditions, making people feel at home doing an activity in the room.

Based on the understanding of ergonomics, the design of work equipment should be adjusted to the size of the body's anthropometry. It is often found that the design or thinking of harmonizing humans and work equipment and improving the workings, in general, is not yet known, not even a few measures of work equipment are not very suitable for the size of the workforce.

\section{B. Method}

1) Development Model: The development model in designing Bentor steering systems is (Research \&
Development). Referring to some opinions of experts who stated that development research aims to develop and produce a product in the form of models, methods, media, tools, and strategies that are valid [13].

In this case, a steering system and Bentor model will be developed that can add to the safety and comfort of both passengers and drivers. Model development is meant by combining the motorbike frame with the front body where the passengers sit and adding a direct steering system using a tie rod to move the wheel when turning so that the driver does not tilt his body to turn.

2) Product Development Procedure: The procedure (stages) of designing R \& D, is a stage or steps to develop an existing product to be perfect. Therefore, in this design the development stages that will be used, referring to the stages of research according to Borg and Gall [14] which are modified into five stages, namely: (1) Requirement analysis phase; (2) design development stage; (3) expert validation and revision stages; (4) the stage of the product design process; and (5) evaluation phase. The modified design flow chart, as in Figure 7 below.

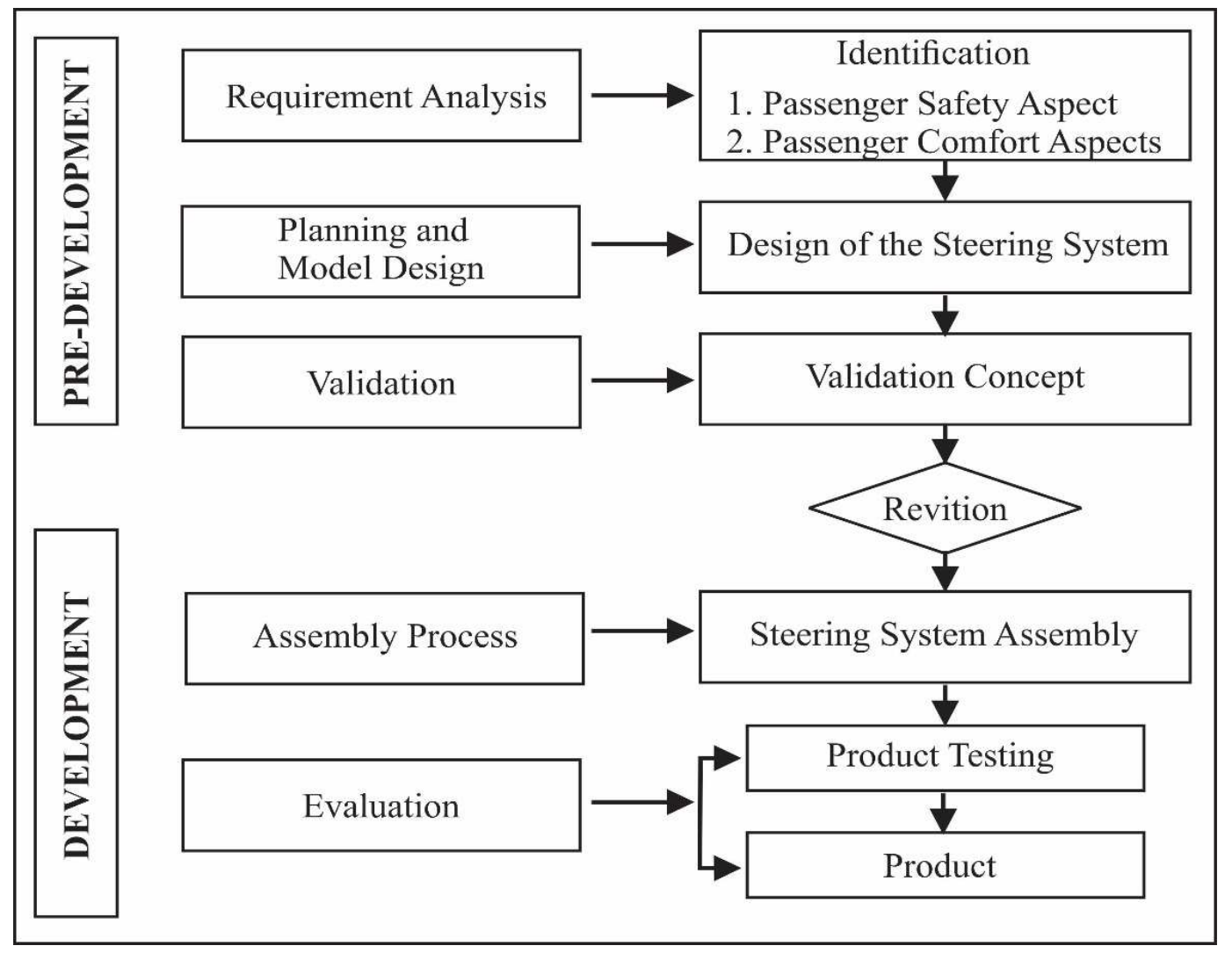

Fig. 7. Bentor Development Procedure

Based on the flow chart in Figure 6, the Phases of development are divided into two main activities, namely pre-development activities which include: (1) the need analysis phase, (2) the design and development phase, and (3) expert validation and revision phase. After revision, continued with development activities which include: (4) design stage; and (5) evaluation phase. Following the planned phases of $\mathrm{R} \& \mathrm{D}$ research, the development activities carried out are limited to the assembly process, development in the concept validation phase. For this reason, the design is to change the bent steering system which has been driving passengers by replacing the steering system using tie-rod. 


\section{RESULT AND DISCUSSION}

\section{A. Result}

1) Development Design Phase: The design development of this activity has produced several designs, namely: (1) the design of a patent passenger model with a motorcycle frame; (2) the steering system with direct drive so that when turning only the moving wheels (3) the use of suspensions and shock absorbers for the softness of the spring movement.

2) Validation and Revision Phase: At this stage, validation is carried out internally on the initial concept. In the framework of conceptual validation, the first step taken is to show the validators, the draft of the design and the initial model developed. The validator configuration consists of three automotive expert lecturers and automotive practitioners, namely Automotive Engineering lecturers, especially Motorcycles, and ergonomics lecturers. The results and suggestions from the validator are used as reference material in revising the initial design. Output at this stage is a design and concept that is valid so that it is worthy of being used as a product and produced.

3) Assembly Process Phase: Next will be continued in the assembly process like a patent passenger with a motorcycle frame, and direct steering system assembly to move the front wheel when turning, so that the driver no longer tilts his body when turning. Next pair the suspension system and shock absorbers on the vehicle suspension system.

4) Product Evaluation: After the assembly stage and paying attention to each process, a trial and evaluation of the modified Bentor are carried out using the direct steering system. Tests carried out by the Bentor driver so that the impact can be felt the difference. From the trial process, there are no errors or damage to the products that have been assembled and the Bentor can run well without any obstacles, so it can be ascertained that the steering system works well and can be produced.

\section{B. Discussion}

The results of the steering system design using a tie rod using 6 (six) tie rods, so that the steering feels lighter. the flow of movement from the steering wheel to the wheels is as follows; the steering shaft rotation moves the pitmen arm to move the steering corner lever placed on the wheel shaft and then steering corner lever moves the two wheels on each axis with a tie rod intermediary.

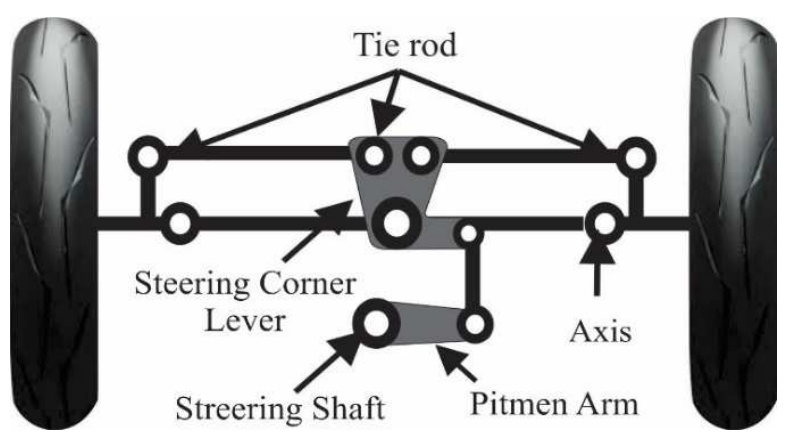

Fig. 8. The design of the steering system using tie rod
Based on the results of the front wheel alignment measurement on the results of the Bentor steering system design using the tie rod are as follows:

Camber angle measurement is $4^{\mathrm{O}}$ for vertical lines. In other words, the outward sloping wheel means the wheel forms a positive camber according to Mr. Park and Sohn opinion that if the outward sloping is called positive camber, and if the sloping inward is called negative camber, the positive camber angle is if the Bentor gets a load the wheel position will form camber 0 (zero).

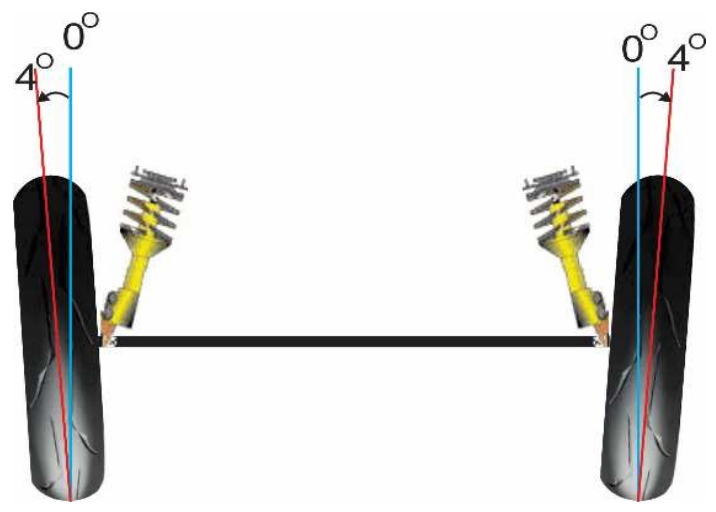

Fig. 9. Results of Camber Angle Measurement

Measuring the Caster angle is an angle of 0 (zero) so that it will be easier to turn the wheel and the steering control is still awake. zero degrees angle makes it easy to turn the steering wheel when the vehicle turns, taking into account the passenger load on the front of the Bentor.

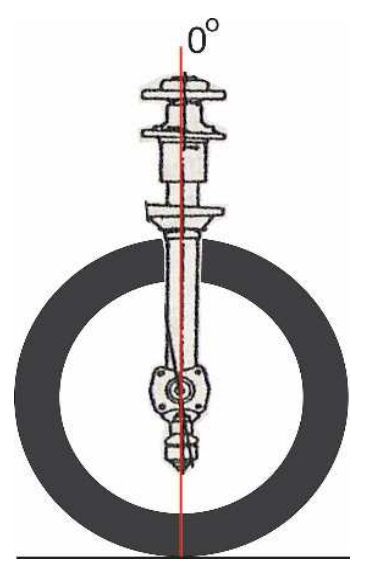

Fig. 10. Results of Caster Angle Measurement

Based on the toe angle of the bent wheel front attitude the distance is $\mathrm{A}=1090 \mathrm{~mm}$ and the distance $\mathrm{B}=1110 \mathrm{~mm}$ which indicates the position of the wheel forming the toe. This is by the Mr. Kooijman opinion that the Vehicle can be called to have toe-in if the front wheel (A) is smaller from the back of the front wheel (B) (seen from above). Instead, the opposite arrangement is called toe out. and expressed in units of $\mathrm{mm}(\mathrm{B}-\mathrm{A})$. 


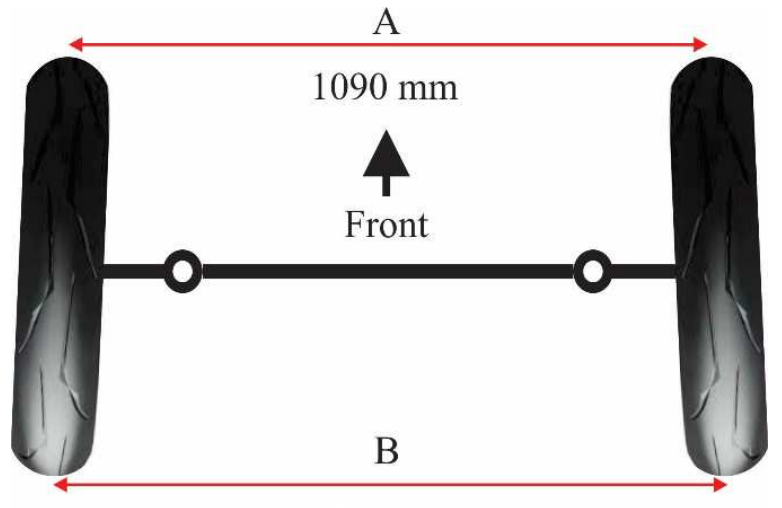

$1110 \mathrm{~mm}$

Fig. 11. Results Wheel Distance Measurement

Turning corners of the Bentor front wheel resulting from the design using a tie rod after the measurement are 40 degrees to the straight forward line so that the bent can turn towards the left and right by $40^{\circ}$.

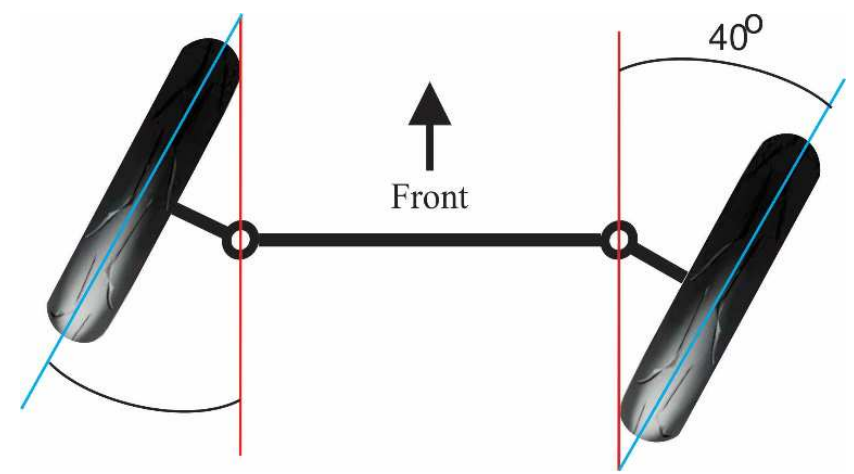

Fig. 12. Wheel Turn Radius

\section{IV.CONCLUSION}

Based on the validation by experts about the steering system that has been designed, taking into account the speed, ease of operation of the steering wheel, material strength and tire resistance. The steering system design concepts, the steering system uses 6 (six) tie rods to maximize working the steering system when walking straight and especially when turning. The steering corner lever commitment can add thrust from the steering shaft by adopting a lever system, so that when you turn it does not require a lot of power to move the wheels. Likewise, the position of the front wheel can help to lighten the steering handlebars.

\section{REFERENCES}

[1] Z. Zulhajji, M. Yahya, and S. Saharuna, "Perancangan Sistem Pengereman Bentor Model Cakram (Design of Bentor Braking System with Disk Model)," Sci. Pinisi, vol. 2, no. 2, pp. 73-150, 2016.

[2] R. Rasyid, G. D. Dirawan, R. Umar, and N. Pertiwi, "Problem and solution of poverty household in Makassar City, Indonesia," Acad. Strateg. Manag. J., vol. 17, no. 6, 2018.

[3] M. Suryani and A. Mashdurohatun, "Penegakan Hukum Terhadap Eksistensi Becak Bermotor Umum (Bentor) Berdasarkan UndangUndang Nomor 22 Tahun 2009 Tentang Lalu Lintas dan Angkutan Jalan (Law Enforcement Against the Existence of Bentor Motorized Pedicab Based on Law Number 22 Year 2009 Conce," J. Pembaharuan Huk., vol. 3, no. 1, pp. 21-38, 2016.

[4] D. Pojani and D. Stead, "Sustainable urban transport in the developing world: beyond megacities," Sustainability, vol. 7, no. 6 , pp. 7784-7805, 2015.

[5] D. G. E. Putra, I. K. A. Atmika, and I. M. Widyarta, "Analisis Kinerja Traksi Kendaraan Roda Tiga Dengan Modifikasi Progresi Geometri Bebas (Analysis of Three-Wheeled Vehicle Traction Performance with Modification of Free Geometry Progression)," 2017.

[6] S. Sano, Y. Furukawa, and S. Shiraishi, "Four Wheel Steering System with Rear Wheel Steer Angle Controlled as a Function of Sterring Wheel Angle," SAE Trans., pp. 880-893, 1986.

[7] N. M. Anguera, "Electrical power steering mechanism of the rack and pinion type for motor vehicles." Google Patents, 25-Feb-1986.

[8] M. Nagai, M. Shino, and F. Gao, "Study on integrated control of active front steer angle and direct yaw moment," JSAE Rev., vol. 23, no. 3, pp. 309-315, 2002.

[9] S.-J. Park and J.-H. Sohn, "Effects of camber angle control of front suspension on vehicle dynamic behaviors," J. Mech. Sci. Technol., vol. 26, no. 2, pp. 307-313, 2012.

[10] J. D. G. Kooijman, J. P. Meijaard, J. M. Papadopoulos, A. Ruina, and A. L. Schwab, "A bicycle can be self-stable without gyroscopic or caster effects," Science (80-. )., vol. 332, no. 6027, pp. 339-342, 2011.

[11] H. D. Taghirad and E. Esmailzadeh, "Automobile passenger comfort assured through LQG/LQR active suspension," J. Vib. Control, vol. 4, no. 5, pp. 603-618, 1998.

[12] A. Albayrak, M. A. Van Veelen, J. F. Prins, C. J. Snijders, H. De Ridder, and G. Kazemier, "A newly designed ergonomic body support for surgeons," Surg. Endosc., vol. 21, no. 10, pp. 1835-1840, 2007.

[13] H. P. Setyosari, Metode penelitian pendidikan \& pengembangan. Prenada Media, 2016.

[14] M. D. Gall, J. P. Gall, W. R. Borg, and M. (Mark) D. Gall, Applying educational research: How to read, do, and use research to solve problems of practice. Pearson, 2014. 